\title{
Discours
}

Revue de linguistique, psycholinguistique et informatique. A journal of linguistics, psycholinguistics and computational linguistics

$12 \mid 2013$

Varia

\section{Self-Repair and Language Selection in Bilingual Speech Processing}

Inga Hennecke

\section{(2) OpenEdition}

Journals

Electronic version

URL: http://journals.openedition.org/discours/8789

DOI: 10.4000/discours.8789

ISSN: 1963-1723

Publisher:

Laboratoire LATTICE, Presses universitaires de Caen

\section{Electronic reference}

Inga Hennecke, "Self-Repair and Language Selection in Bilingual Speech Processing », Discours

[Online], 12 | 2013, Online since 10 July 2013, connection on 01 May 2019. URL : http://

journals.openedition.org/discours/8789; DOI : 10.4000/discours.8789

\section{(c) (1) (9)}

Discours est mis à disposition selon les termes de la licence Creative Commons Attribution - Pas d'Utilisation Commerciale - Pas de Modification 4.0 International. 

Revue de linguistique, psycholinguistique et informatique

\section{Self-Repair and Language Selection in Bilingual Speech Processing}

Inga Hennecke

Ruhr-Universität Bochum 



\title{
Self-Repair and Language Selection in Bilingual Speech Processing
}

\author{
Inga Hennecke
}

Ruhr-Universität Bochum

In psycholinguistic research the exact level of language selection in bilingual lexical access is still controversial and current models of bilingual speech production offer conflicting statements about the mechanisms and location of language selection. This paper aims to provide a corpus analysis of self-repair mechanisms in code-switching contexts of highly fluent bilingual speakers in order to gain further insights into bilingual speech production. The present paper follows the assumptions of the Selection by Proficiency model, which claims that language proficiency and lexical robustness determine the mechanism and level of language selection. In accordance with this hypothesis, highly fluent bilinguals select languages at a prelexical level, which should influence the occurrence of self-repairs in bilingual speech. A corpus of natural speech data of highly fluent and balanced bilingual French-English speakers of the Canadian French variety Franco-Manitoban serves as the basis for a detailed analysis of different self-repair mechanisms in code-switching environments. Although the speech data contain a large amount of code-switching, results reveal that only a few speech errors and self-repairs occur in direct code-switching environments. A detailed analysis of the respective starting point of code-switching and the different repair mechanisms supports the hypothesis that highly proficient bilinguals do not select languages at the lexical level.

Keywords: self-repair, Hesitation and Monitoring Phenomena, bilingualism, lexical access, speech production

Le niveau exact de la sélection des langues lors de l'accès lexical chez le bilingue reste une question controversée dans la recherche psycholinguistique. Les modèles actuels de la production verbale bilingue proposent des arguments contradictoires concernant le mécanisme et le lieu de la sélection des langues. La présente recherche vise à fournir une analyse de corpus mettant l'accent sur les mécanismes d'autoréparation dans le contexte d'alternance codique dans la production verbale de bilingues très compétents. Le présent travail retient les hypothèses du modèle Selection by Proficiency selon lequel les compétences linguistiques et la robustesse linguistique déterminent le mécanisme et le niveau de la sélection des langues. Conformément à cette hypothèse, les locuteurs bilingues très compétents choisissent une langue à un niveau pré-lexical. Par conséquent, cela devrait influencer la manifestation d'autoréparations dans les situations d'alternance codique. Un corpus de langage parlé de locuteurs du canadien français franco-manitobain, bilingues équilibrés anglais-français, sert de base pour une analyse approfondie des différents mécanismes d'autoréparation. Bien que les données du corpus soient fortement empreintes d'alternance codique, seulement peu d'autoréparations apparaissent dans des situations d'alternance codique. Une analyse approfondie, prenant en compte le point de départ respectif de l'alternance codique ainsi que la classification des autoréparations, soutient l'hypothèse que la sélection des langues dans la production verbale ne se fait pas au niveau lexical chez les locuteurs bilingues équilibrés.

Mots clés: autoréparation, phénomènes d'hésitation et de contrôle, bilinguisme, accès lexical, production verbale 


\section{Introduction}

Speech repair mechanisms reveal important peculiarities of language processing and the mental lexicon. Before the evolution of modern psycholinguistic experimental technologies and methodologies, the analysis of speech repair constituted an important tool for researchers to gain insight into the processes of lexical access and monitoring of speech processing. The present paper proposes a corpus analysis of self-repair mechanisms in code-switching sequences to approach the problem of language selection in bilingual speech. The intention of the present study is twofold. On the one hand, it provides a qualitative analysis of self-repair mechanisms in a corpus of highly fluent French-English bilinguals. On the other, it aims to apply the results from the corpus analysis to current models of lexical access in bilingual speakers. The present paper relies on the assumption that speech errors and their repair mechanisms can give important insights into the question of language selection in bilingual speech processing.

In former research, self-repair mechanisms were mainly analyzed from a conversation analysis perspective (e.g., Schegloff et al., I977; Jefferson, 1983; Gülich, 1986; Gülich \& Kotschi, 1987; Kotschi, 1996). These authors focused on self-initiated self-repairs as an important phenomenon for the linguistic analysis of language processing and the role of self-repair mechanisms in conversation. Schegloff et al. (1977) observed that self-repair mechanisms do not appear randomly, but are highly organized phonologically and morphosyntactically. Gülich and Kotschi emphasized that the main interest of repair mechanisms lies in the sequential organization of the whole conversation (e.g., Gülich \& Kotschi, 1987; Kotschi, 1996).

Recent studies broaden the perspective of conversation analysis in self-repair, in that they focus on cross-linguistic comparisons of speech repair mechanisms (Fox et al., 1996; Rieger, 2003; Uhmann, 2006; Fox et al., 20IO). These studies aim to analyze the interaction of language-specific characteristics and the preference for certain self-repair mechanisms. The results of these studies provide evidence that speakers of different languages resort to different strategies to deal with repair sequences (e.g., Fox et al., 2010). Fox et al. (2010: 2503) observed that even related languages, such as English and German, have recourse to different repair practices. In contrast, languages that are less closely related, such as German and Hebrew, may resort to similar practices (Fox et al., 2010: 2503).

In addition to a conversation analysis perspective on self-repair mechanisms, it is also possible to approach this phenomenon from a psycholinguistic perspective (e.g., Levelt, 1983). Levelt examined the different functions of self-repair in communication and established a more detailed classification of repair mechanisms into error repairs, appropriateness repairs, different message repairs and covert repairs. Error repairs correct wrong utterances that were expressed accidentally, appropriateness repairs add hearer-relevant information, while different message repairs initiate a speaker-relevant turn. The covert repairs in Levelt's classification are termed Hesitation and Monitoring Phenomena (HMP) in current research, because they 
do not necessarily result in a repair. The present study will adopt the classification of self-repair mechanisms established by Levelt. The term covert repair will not be employed in the following analysis. This classification is modified slightly by taking into account the differentiation between replacement and recycling. This differentiation has already been considered in other studies in varying definitions (see Fox \& Jasperson, 1995; Rieger, 2003; Fox et al., 2010). Fox et al. (2010) classify a self-repair as a replacement if an item is replaced by another, as in:

[I] What was this I heard about them going up to Monarch and writing* (O.5) spray painting something on Monarch?

(Fox et al., 2010: 2488)

In contrast, a self-repair is classified as a recycling if "a speaker mispronounced a word and then re-produced it with a more appropriate pronunciation" (Fox et al., 2010: 2489), as in:

[2] Is there a more perfect guy to fit the Jo-* Jets organization?

(Fox et al., 2010: 2489)

At first sight, both examples seem to be instances of Levelt's appropriateness repairs. Still, this differentiation may be especially crucial in bilingual contexts. In Fox et al. (2010) the concept of recycling is restricted to phonological properties and has to be expanded to fit into the present analysis. In the present understanding, a recycling includes the repetition of a lexical item in the same language, whereas a replacement involves the repetition of a word in the other language (see Section 5).

The present study focuses on self-repair mechanisms in bilingual speech, and more precisely in code-switching environments. For this reason, the next section of this paper introduces recent findings on self-repair and monitoring processes in bilingual speech. In the third section, current models of lexical access in bilingual speech production will be presented, with a special focus on the Selection by Proficiency (SbP) model by Schwieter and Sunderman (2008). This section discusses what insights self-repair mechanisms in bilingual speech can give about the level of language selection in bilingual language processing. The fourth section of this paper introduces the corpus data of highly fluent French-English bilinguals, which will be analyzed and discussed in the following section. Here, the focus will lie on the different types of self-repair and their positioning in the code-switching sequence.

The overall aim of this analysis is to clarify the role of self-repair mechanisms in bilingual speech processing and to identify their possible impact on research about language selection in bilingual lexical access.

\section{Self-repair and monitoring in bilingual speech}

Self-repair strategies in monolingual speech are highly organized, but they may vary from language to language (Fox et al., 20IO). But, according to Grosjean, speakers 
are in a bilingual mode when they use bilingual speech (cf. Grosjean, 200I). In this case, self-repair mechanisms from both languages are activated and speakers can access strategies from either one language or the other (Hlavac, 20II). There are few concrete studies on the role of self-repair mechanisms in bilingual speech (e.g., Rieger, 2000). In the following, selected studies will be introduced to provide an overall picture about the role of repair mechanisms in bilingual speech. To give an overview about possible HMP in bilingual speech, Hlavac (20II) established a classification that includes repairs:

I. Unfilled pauses;

2. Filled pauses (non-lexicalized);

3. Filled pauses (lexicalized);

4. False starts (pre-positioned);

5. Backtracking, repairs (post-positioned);

6. Explicit pre-empting (pre-positioned);

7. Explicit justification (post-positioned);

8. Paralinguistic markers: laughter, nervous coughing (pre- and post-positioned); 9. Equivalents from Croatian accompanying English code-switches.

(Hlavac, 20Ir: 3798)

On the basis of this classification, Hlavac performed a large-scale corpus analysis of second-generation Croatian-English bilinguals. He examined whether the above-named HMP occur extremely frequently in code-switching examples or not. His results suggest that "different types of code-switches attract higher or lower frequencies of HMP, depending on their phonological and/or morphological form" (Hlavac, 20II: 3793). He differentiates between three kinds of code-switching, namely (I) intra-clausal code-switching, (2) inter-clausal code-switching, and (3) extra-clausal code-switching (Hlavac, 20II: 3797-3798). According to his analysis the most important type of code-switching for self-repair seems to be intra-clausal code-switching. In his data, he detected that only $2.6 \%(n=4 / 155)$ of the overall occurrences of false starts, repairs and backtracking occur in environments of intra-sentential code-switching (Hlavac, 2oII: 3799). When referring to intrasentential code-switching, Hlavac mostly relies on insertional code-switching and does not sufficiently consider alternational code-switching. In contrast, the present analysis focuses primarily on alternational code-switching (see Section 5 ). This choice is motivated by the fact that it is not always unequivocally clear how to define insertional code-switching and how to differentiate it from borrowings or other language contact phenomena. Furthermore, the present corpus data contain a significantly higher number of alternational code-switching occurrences than insertional code-switching instances (see Section 5).

Fehringer and Fry (2007) examined the role of hesitation phenomena such as filled pauses, automatisms, repetitions and reformulations in the Li and the L2 of highly proficient bilingual English-German speakers. They collected and analyzed natural speech data in which participants completed an interview, story-telling and 
a memory task. Their results suggest that even highly fluent bilingual speakers produce more hesitation phenomena when speaking in their L2 and they explain this tendency by a higher cognitive load in L2 speech (Fehringer \& Fry, 2007: 37). They furthermore suggest that specific hesitation mechanisms from Li are mirrored in L2 (Fehringer \& Fry, 2007: 37). The explanation of a higher cognitive load seems to be quite imprecise and insufficient with regard to the complex nature of bilingual lexical access. In current models of bilingual lexical access, the degree of interconnectivity between the two languages and the exact level of language selection remain unsolved issues. Therefore, the upcoming section aims to give an overview about the problems and questions in modelling bilingual lexical access with regard to self-repair mechanisms and code-switching.

\section{Bilingual lexical access in speech production}

If two languages are interconnected in the bilingual brain, then bilingual speakers should have particular problems in accessing the right lexical form from the right language. It is commonly assumed in bilingual lexicon models that the two languages share a common conceptual level and differ only at the lexical and feature level. This should lead to more problems, such as hesitations and self-repairs, in speech production in bilingual than in monolingual speakers because representations from both languages can be activated in the lexical retrieval process. That is to say, bilingual speakers have access to the phonological, lexical, semantic and syntactic information of two languages and that should complicate the process of lexical access in speech processing. This problem, referred to as bilingual disadvantage (Gollan et al., 20o8), should lead to a higher number of speech errors in bilingual speech than in monolingual speech. In reality, bilingual speakers commonly have few problems in accessing the right word from the right language at the right moment. Still, bilingual models of bilingual speech production vary strongly in how to explain the concrete nature of lexical access. Most current models rely on the assumption that bilingual lexical access is, at least partly, a competitive process in which the two languages compete for activation.

The following two models assume that lexical access is competitive at the lexical level, that is to say that the two languages compete for activation in bilingual speech processing.

Costa et al. (1999) assume in their lexical access model that lexical access is language specific, while both languages share a common conceptual and semantic level. In this model, language selection is not competitive at the lexical level and both languages can be activated in parallel (Costa et al., 2000: 430). The assumption that lexical access is completely language-specific at the lexical level has been challenged by a wide range of research (e.g., Green, 1986 and 1998; Meuter \& Allport, 1999; Gollan et al., 2002 and 2008). The Inhibitory Control Model (ICM) by Green (1986; 1998) proposes a shared lexical level in which all lexical representations are tagged with a language node (Green, 1998). Green (1998) also takes into account language 
proficiency and proposes that inhibitory mechanisms are stronger when the $\mathrm{L}_{\mathrm{I}}$ has to be suppressed, because the Li generally receives more activation from the conceptual level. Other current research has provided additional evidence for the assumption that language proficiency is a relevant factor in bilingual lexical access (Meuter \& Allport, 1999; Costa \& Santesteban, 2004; Schwieter \& Sunderman, 2008).

Another approach to bilingual lexical access is proposed by Gollan et al. (2002; 2008; 20II) in terms of the "weaker link hypothesis" (2008). This hypothesis does not consider lexical access as a competitive process, but relies on the proposal that bilinguals are disadvantaged compared to monolinguals in lexical access. This disadvantage can be attributed to the imbalances in frequency in words in the two languages. That is to say, depending on different factors, words from one language are chosen in a given situation over words from the other language. This imbalance in the choice of words from one language leads over time to an imbalance in frequency of use and to weaker links to the semantics and phonology of the respective language system (Gollan et al., 2008).

While all these models rely on different mechanisms for language selection, they also assume that the interaction between the two languages may take place on different levels of bilingual lexical access. According to these models, language selection may be specific and not competitive at a lexical level (Costa et al., 1999), competitive and controlled by inhibitory control mechanisms at a lexical level (Green, 1986) or frequency-driven and controlled by weaker or stronger links (Gollan et al., 2008). The fact that the speech data of highly proficient bilingual speakers generally contain a large amount of code-switching may lead to the assumption that language selection may not be exclusively language-specific and that the two languages are, at least to some degree, interconnected at the lexical level. The evidence of codeswitching data is however still ambiguous for the modelling of bilingual lexical access. Meuter and Allport (1999) performed experiments with bilingual speakers who named digits on a screen in their Lr or their L2, depending on the screen colour. They detected that bilinguals suffer more switching costs when switching into their more dominant language Lr than into their less dominant language L2. This phenomenon is commonly referred to as bilingual asymmetry. Counterevidence has been provided by Costa and Santesteban (2004), who performed picture naming in a language-switching task with Spanish-Korean and Korean-Spanish learners and with highly proficient Spanish-Catalan bilinguals. While they observe a switching cost from the L2 to the LI in learners, they report a symmetrical switching cost in highly proficient bilinguals, even in their weaker languages. This leads to the assumption that language proficiency may influence the switching costs of bilingual speakers. Schwieter and Sunderman (2008) considered the role of language proficiency and established the SbP model (see Figure I). This model posits that language proficiency is an important variable in bilingual lexical access. Less proficient bilinguals perform lexical access by means of an inhibitory control mechanism while highly proficient bilinguals can resort to a language-specific control mechanism in the form of a preverbal message. The preverbal message contains specific information about the 
target language, the linguistic register and the respective concept (Schwieter \& Sunderman, 2008: 233). In this case, lexical competition does not occur at a lexical level and therefore no inhibitory mechanism is needed.

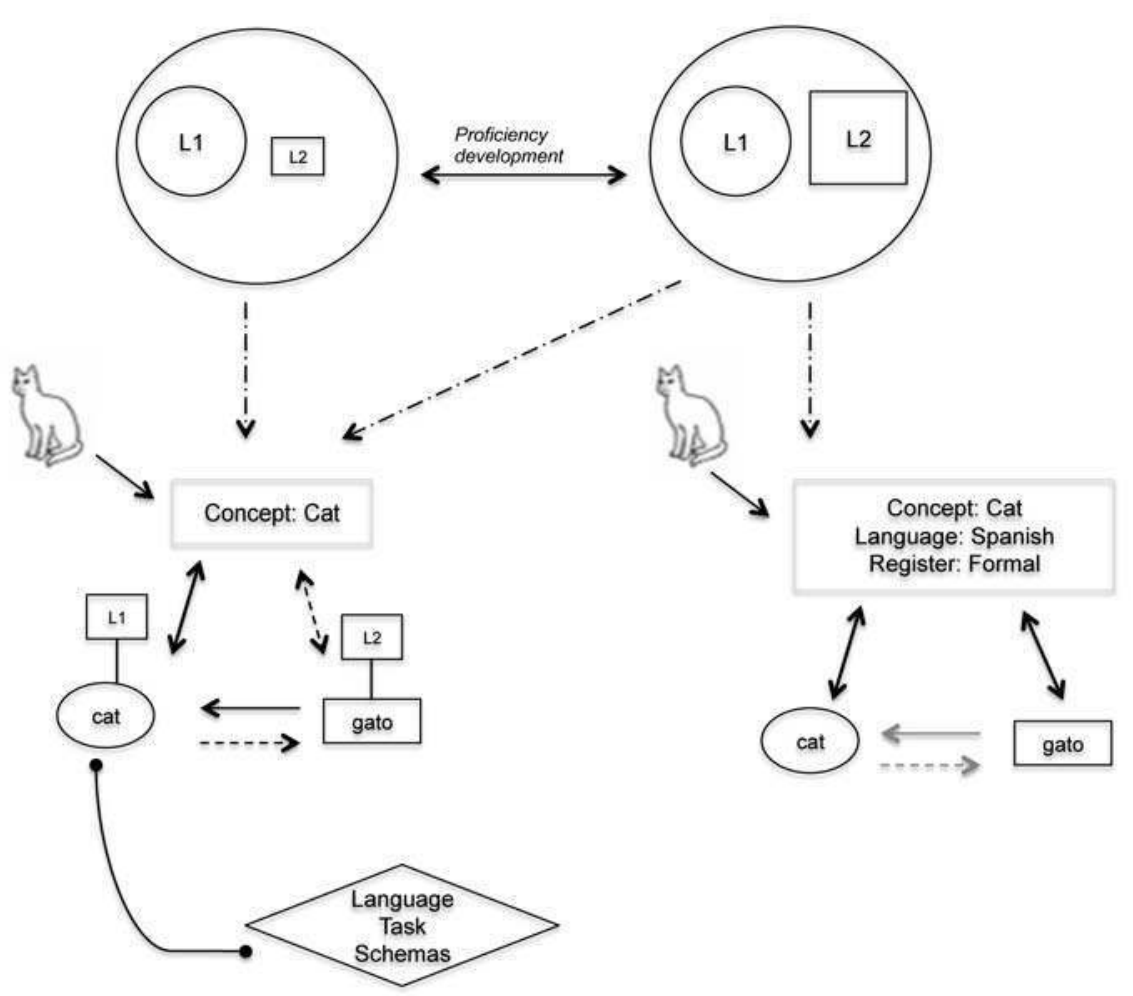

Figure 1. The SbP model adapted from Schwieter and Sunderman (2008: 232)

To provide empirical evidence for their model, the authors first measured the verbal fluency of English-Spanish learners. In a second step, the participants performed a picture-naming task with language switches, based on Costa and Santesteban (2004). They report main effects in verbal fluency, language and trials that indicate that less proficient speakers with less verbal fluency have more switching difficulties. Their results indicate that the shift from an inhibitory control mechanism to a language-specific control mechanism is based on L2 lexical robustness (Schwieter \& Sunderman, 2008: 230). They conclude on their findings by defining lexical robustness "as the point in which bilinguals will no longer have to primarily rely on inhibitory control" (Schwieter \& Sunderman, 2008: 234). The concept of a preverbal message, as defined by Schwieter and Sunderman (2008) remains somewhat vague and its exact nature still has to be determined. Still, the overall concept of the SbP model will be adopted in the present study, i.e., the notion that highly fluent bilinguals already choose languages at a prelexical level whereas less fluent bilinguals rely on an inhibitory control mechanism at the lexical level. 
With regard to self-repair mechanisms, the level of language selection is extremely important. If highly proficient bilinguals do not select languages at the lexical level, they should not perform speech errors in bilingual environments, or more precisely in code-switching situations. This would imply that they perform fewer self-repairs in code-switching environments than monolingual speakers or L2 learners. This is because language is already selected at this moment of speech processing in highly fluent bilinguals. This hypothesis is supported by the results of the large-scale data analysis in Hlavac (20II), where only $2.6 \%$ of the instances of false starts, repairs and backtracking occur in intra-sentential code-switching environments. To test this hypothesis, it is important to differentiate adequately between different types of self-repair mechanisms.

It has to be specified that not all self-repair mechanisms occur only at a lexical level. Error repairs and recyclings do not necessarily require reinitiation of the processing process. Still, recyclings cannot provide any important information about the level of language selection, because they imply the repetition of a lexical item from the same language. In contrast, different message repairs and appropriateness repairs include the verbalization of a new concept or idea and therefore imply the return to a prelexical level. In accordance with the above-formulated hypothesis, it is assumed that different message repairs, appropriateness repairs and recyclings may appear frequently in code-switching environments while error repairs and replacements do not. The most interesting process to analyse the level of language selection is the self-repair mechanism of replacement, because it assumes the replacement of a lexical item from one language by an equivalent item of the other language. If highly fluent bilinguals indeed select languages at a prelexical level, then replacements should not appear frequently in the bilingual corpus data. This prediction complies with the SbP model by Schwieter and Sunderman (2008).

\section{Methodology}

\subsection{Participants and data collection}

The corpus data used for the present analysis come from the Canadian French variety spoken in Manitoba, Franco-Manitoban. The French language in Manitoba experienced a separate evolution from other French Canadian varieties and a longterm influence of the English language. Due to its sociolinguistic and historical evolution, spoken Franco-Manitoban is highly influenced by English and speakers include a large amount of English vocabulary and code-switching in their everyday conversations.

The present corpus data, called the Franco-Manitoban corpus (FM corpus) in the following, was collected in September 2010 in the French quarter of Winnipeg, Saint-Boniface. It contains 35,660 tokens overall, distributed into I5 conversations by a total of 20 speakers. All speakers were aged between 17 and 30 years old and were born and raised in the Franco-Manitoban environment of Saint-Boniface or 
neighbouring districts. The language distribution of English and French in the data is unbalanced; French represents two thirds of the data while English only accounts for one third (see Figure 2).

All recordings were collected through participatory and non-participatory observation in non-guided and informal situations in Saint-Boniface. The interviewer did not induce or conduct the conversations but was simply present as a silent observer. In case of absence of the interviewer, a member of the respective group of speakers collected the recordings. The presence of the interviewer did not influence the speakers' communication habits in a negative way, due to the long-term familiarity of the interviewer with the Franco-Manitoban community. The communications were not especially induced for the recordings and the speakers selected the topics of conversation freely and regardless of the presence or absence of the interviewer. The degree of French and English language proficiency of the speakers was determined by self-assessment of the speakers as well as a sociolinguistic questionnaire, established by Mougeon et al. (2005). All speakers indicated that they identified themselves strongly with the Franco-Manitoban culture and took an active part in the cultural and social life of the community. They all indicated the French language as their mother tongue and try to use French as the matrix language when communicating. All speakers were identified as highly fluent and balanced bilingual speakers of English and French. They followed a purely French education at least until the age of 17 that is to say until completing high school. Due to the sociolinguistic circumstances they were regularly exposed to the English language in everyday life from an early age. Regardless of the fact that all speakers indicate French as their Li, they are very aware of the impact of the English language on their communication habits. In the course of personal conversations that do not figure in the transcribed speech data, most speakers indicated having the impression that English has a negative influence on their French language skills, which often results in language insecurity.

\subsection{Transcription and data coding}

The speech data was transcribed according to HIAT-conventions (e.g., see Ehlich $\&$ Rehbein, 1976). Pauses up to one second are displayed as $\bullet$ (pauses shorter than $0.25 \mathrm{sec}$.), $\bullet$ (pauses of half a second) or $\cdots$ (pauses up to three-quarters of a second). Pauses of one second or longer are indicated in double brackets, such as $((\mathrm{I} .3 \mathrm{sec})$.$) . The point of repair is displayed with the sign /. To highlight the$ relevant parts in the following examples, the repair situation is underlined and the code-switching situation is marked in italics. In the transcriptions, all the speakers and other people, organizations and personal data mentioned are anonymised.

The overall token distribution of the corpus data is represented in Figure 2. Sounds such as $e b m$, ob and $a b$, as well as laughter, were classified as non-lexical sounds; false starts are defined as lexemes that were interrupted before they could clearly be assigned to one language. Cognates were assigned to French or English based on the phonological information in the actual speech recordings. 


\section{FM corpus}

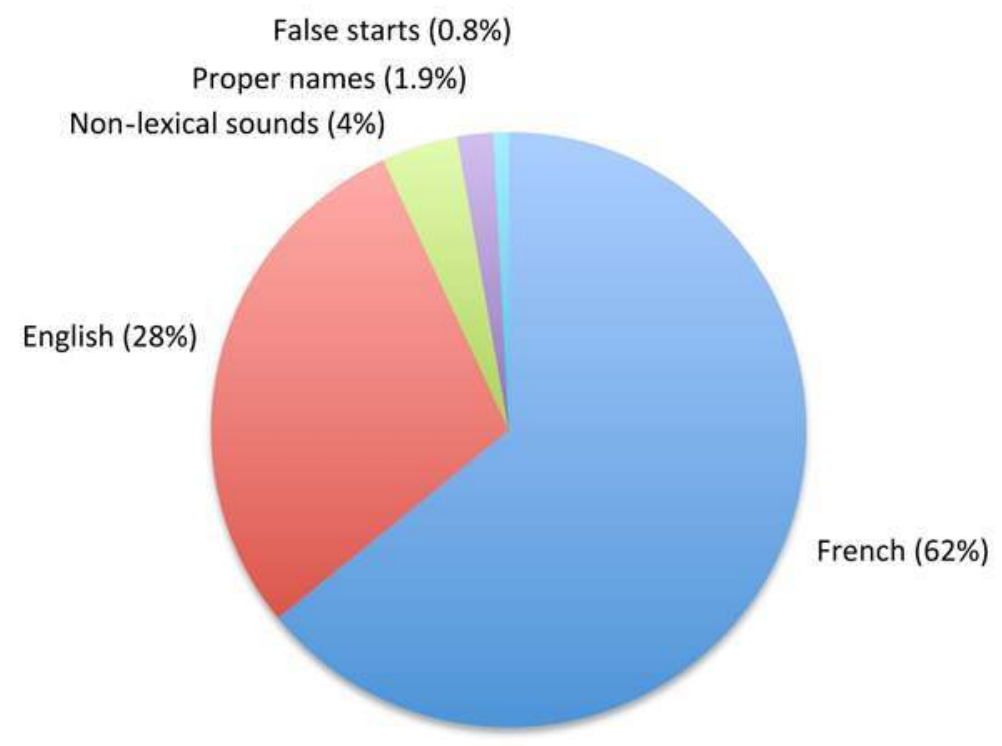

Figure 2. Overall token distribution of the FM corpus data

\section{Analysis} ((I.3 sec.)) high chair [...]. such as in:

The special focus of the analysis is on different mechanisms of self-repair in code-switching environments. Unless indicated otherwise, all upcoming examples are taken from the corpus data described here.

As stated in the previous section of this paper, the present corpus data contain an overall number of 35,660 tokens; $62 \%$ of the speech data is uttered in French and $28 \%$ of the speech data in English. The present analysis focuses on self-repair mechanisms as defined above and does not include instances of word finding processes, such as:

[3] WIL: the news thing c'est elle a son $\bullet$ son $\bullet$ son eh $\bullet \bullet$ eh eh pas change table voyons

Furthermore, the analysis does not consider pure hesitation phenomena in code-switching environments that do not coincide with self-repair mechanisms,

[4] WIL: so là quand on dit c'est le temps de manger $\cdots$ si on enlève la table $d u$ bigh chair $\bullet$ she'll climb the bigh chair puis (gets herself in).

After exclusion of the above-mentioned data, the corpus data contain a total of 856 self-repairs. Out of these 856 self-repairs only $8.5 \%(n=73 / 856)$ occur in a bilingual 
environment. The bilingual environment of the code-switches can be of varying nature; code-switching may occur from French to English and vice versa. Regarding the type of code-switching, $26 \%(\mathrm{n}=19 / 73)$, can be classified as insertional codeswitching, whereas $74 \%(n=54 / 73)$ of the occurrences are classified as alternational code-switching. The length of the code-switch may vary from one-word switches (insertional code-switching) (example [5]) to continuing the whole conversation in the respective language (alternational code-switching) (example [6]):

[5] JA: (()) ils connaissent pas les bike shops là / là pour réparer là (( ))

[6] WIL: de plus en plus face à du monde qui essayent de / trying to push me their way around.

Furthermore, the starting point of code-switching is important with regard to the actual self-repair. Code-switching may start just before the self-repair process, during the self-repair or just after. Despite the unbalanced occurrence of the two languages in the data, the direction of code-switching is relatively balanced. $42 \%$ $(n=31 / 73)$ of the occurrences are code-switches from English to French, whereas $58 \%$ $(n=42 / 73)$ of the switches are from French to English. The variable of the starting point of code-switching and the direction of the switch in the data is presented in Table I. The numbers in brackets indicate the raw figures:

\begin{tabular}{|l|l|l|l|}
\hline & Total & French-English & English-French \\
\hline Before repair & $25 \%(\mathrm{I} 8 / 73)$ & I2\% (9/73) & I2\% (9/73) \\
\hline During repair & $49 \%(36 / 73)$ & $30 \%(22 / 73)$ & $19 \%(14 / 73)$ \\
\hline After repair & $26 \%(19 / 73)$ & $15 \%(\mathrm{II} / 73)$ & II\% (8/73) \\
\hline
\end{tabular}

Table 1. Starting point of code-switching

While the distribution of the starting point of code-switching before and after the repair is relatively balanced, it is still striking that in $49 \%$ of the occurrences, the actual self-repair is the point where a switch of languages occurs. The following examples represent cases where code-switching occurs before the actual self-repair situation:

[7] ZA: j'ai • j'ai parlé à mon ami Jim puis $\bullet$ be’s like / he can't make it either.

[8] WIL: John doesn't do the montbly ((I.7 sec.)) comme les / les retenus à la source •

[9] FLO: t'es tu en train de dire que it / oh it's not gonna happen [...].

In these examples, the self-repair includes planning difficulties in the sequencing of the speaker's utterance. The following examples represent code-switching during the self-repair process: 


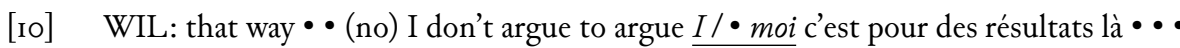

[II] SA: ben j'ai vu comme / ya I heard of it but I never / I never • •

[12] ZA: c'est eux qui s'occupent de la distribution c'est / they do all the work for me and submit it.

In [Io], the repair consists of the repetition of the English lexical item $I$ in French, moi. In contrast, example [II] includes the reformulation of an idea, which would be classified as an appropriateness repair in Levelt's terms. Furthermore, example [I2] represents a self-repair situation in which the speaker feels the need to add some information that may be relevant for the hearer. In Levelt's words, this repair can be classified as a different message repair.

The examples below attest code-switching appearing after the actual repair:

[i3] PJ: sonne comme si qu'ils sont s / comme super secret of / about it • •

[I4] ZA: ya $\bullet$ c'est / c'est totally le genre $\bullet$ that grows on you once

In [13], the pragmatic marker comme is uttered in French before the actual code-switch. This leads to the assumption that the speaker has to deal with planning difficulties and therefore switches to English. A somewhat similar case can be found in [I4], where the speaker repeats the lexical item c'est before switching languages, then switches back to French and, after an unfilled pause, continues in English.

The exact role of the starting point of code-switching in the different self-repair mechanisms will be considered in the following section. As stated above, it was decided to first classify the occurrences of self-repairs in bilingual speech according to Levelt (1983) that is into error repairs, appropriateness repairs, and different message repairs. Furthermore, the differentiation between a recycling and a replacement is included in the present analysis.

As already mentioned in Section $\mathrm{I}$ of this paper, a recycling includes the repetition of a lexical item from one language in a self-repair situation, as in:

[is] WIL: [...] qu'on soit reconnu pour ça $\bullet$ you know and / and / • and que $\bullet$ à cause de ça qu'on a un meilleur impact.

[I6] WIL: but you know like c'est ça / c'est ça l'affaire là like $\bullet$ but $・$ but I mean [...].

In contrast, a replacement includes the replacement of a word in one language by a possible translation equivalent of the other language, as in the following examples:

[I7] SA: comme $\bullet \bullet$ ya la prochaine place que jaimerais / I'd really like to $\bullet$ go to $\bullet \bullet$ Asia.

[18] WIL: est-ce que / je commence à me demander do we just / est-ce qu'on commence à faire des liens avec $\bullet[\ldots]$. 
In the present understanding, an appropriateness repair adds hearer-relevant information but does not include a replacement or a recycling. This self-repair mechanism is illustrated in the examples below:

[ig] SA: ((r.8 sec.)) ya comme / • récemment les deux derniers an / étés like I've just been relaxing a lot.

[20] PJ: il y avait une $\cdots$ like $\cdots$ they took the wrong / $・$ basically il y en a / on / on a envoyé deux •

[2I] WIL: • c'est ça qui est fun du Francoconseil c'est que / ben fun • moi je dis fun là d'autres / d'autres may say otherwise [...].

All these examples demonstrate different kinds of appropriateness repairs. In [19], the speaker intends to say les deux derniers ans then interrupts and corrects les deux derniers étés, which is a more appropriate lexical choice. In [20], the speaker starts to talk about a t-shirt design and then adds for appropriate reasons that they sent two t-shirt designs to the respective agency. In example [2I], the speaker explains his lexical choice for the lexeme fun, which may not be the appropriate term.

In contrast to the appropriateness repair, the different message repair does not add hearer-relevant information but initiates a speaker-relevant turn, as in:

[22] GR: on n'a pas un $\underline{\bullet} /$ well it's gonna take a while if it's gonna happen

[23] SA: like - there's comme / do you know like kitesurfing? comme quand tu va sur les / les vagues?

In both examples, the speakers start a certain utterance, then interrupt and start a new utterance with a different message. In contrast to different message and appropriateness repairs, error repairs describe the case when the speaker starts to use the wrong lexeme and then corrects this speech error:

[24] SA: puis là elle fait sa maitrise en psycholo / en / en social works.

[25] ZA: holy c'est naze! l/ Antoine is gotta get one of these!

The total distribution of self-repair mechanisms in bilingual environments is represented in Table 2 below. It demonstrates that the self-repair mechanisms in the present corpus data can most frequently be classified as recyclings and different message repairs. Recyclings occur just as often in French-English as in English-French code-switching environments, whereas different message repairs occur twice as often in French-English switching contexts as in English-French switching contexts. Furthermore, it is striking that recyclings appear twice as often as replacements. Hesitations and pure appropriateness repairs only occur on a low frequency basis. 


\begin{tabular}{|l|l|l|l|}
\hline & Total & French-English & English-French \\
\hline $\begin{array}{l}\text { Appropriateness } \\
\text { repair }\end{array}$ & $8 \%(6 / 73)$ & $4 \%(3 / 73)$ & $4 \%(3 / 73)$ \\
\hline $\begin{array}{l}\text { Different } \\
\text { message repair }\end{array}$ & $26 \%(\mathrm{I} 9 / 73)$ & $\mathrm{1} 8 \%(\mathrm{I} 3 / 73)$ & $8 \%(6 / 73)$ \\
\hline Error repair & $16 \%(\mathrm{I} 2 / 73)$ & $8 \%(6 / 73)$ & $5 \%(4 / 73)$ \\
\hline Hesitation & $4 \%(3 / 73)$ & $\mathrm{I} \%(\mathrm{I} / 73)$ & $3 \%(2 / 73)$ \\
\hline Replacement & $15 \%(\mathrm{II} / 73)$ & $7 \%(5 / 73)$ & $8 \%(6 / 73)$ \\
\hline Recycling & $30 \%(22 / 73)$ & $\mathrm{IO} \%(\mathrm{II} / 73)$ & $15 \%(\mathrm{II} / 73)$ \\
\hline
\end{tabular}

Table 2. Self-repair mechanisms and direction of code-switching

\begin{tabular}{|l|l|l|l|l|}
\hline & Total & Before repair & During repair & After repair \\
\hline $\begin{array}{l}\text { Appropriateness } \\
\text { repair }\end{array}$ & $8 \%(6 / 73)$ & $\mathrm{I} \%(\mathrm{I} / 73)$ & $\mathrm{I} \%(\mathrm{I} / 73)$ & $5 \%(4 / 73)$ \\
\hline $\begin{array}{l}\text { Different } \\
\text { message repair }\end{array}$ & $26 \%(\mathrm{I} 9 / 73)$ & $\mathrm{I} \%(\mathrm{I} / 73)$ & $25 \%(\mathrm{I} 8 / 73)$ & 0 \\
\hline Error repair & $\mathrm{I} 6 \%(\mathrm{I} 2 / 73)$ & $4 \%(3 / 73)$ & $7 \%(5 / 73)$ & $5 \%(4 / 73)$ \\
\hline Hesitation & $4 \%(3 / 73)$ & 0 & $3 \%(2 / 73)$ & $\mathrm{I} \%(\mathrm{I} / 73)$ \\
\hline Replacement & $\mathrm{I} 5 \%(\mathrm{II} / 73)$ & 0 & $\mathrm{I} 4 \%(\mathrm{I} 0 / 73)$ & $\mathrm{I} \%(\mathrm{I} / 73)$ \\
\hline Recycling & $30 \%(22 / 73)$ & $\mathrm{I} 8 \%(\mathrm{I} 3 / 73)$ & 0 & $\mathrm{I} 2 \%(9 / 73)$ \\
\hline
\end{tabular}

Table 3. Self-repair mechanisms and starting point of code-switching

Table 3 shows that different message repairs and replacements almost entirely coincide with a code-switching starting point during the repair mechanisms. Recycling exclusively co-occurs with a code-switching starting point before or after the actual repair. The difference in the starting point of code-switching between recyclings and replacements is not surprising in that a replacement, by definition, implies a code-switch during the repair. In contrast, a recycling comprehends the repetition of a lexeme in the respective language, which excludes a code-switch situation during the repair. Still, the clear distribution of the code-switching starting point in different message repairs is indeed striking. The reasons for this uneven distribution can only be speculated upon, but it seems as if a different message repair is more suited for a direct code-switch than for instance error repairs. This may be due to the fact that in different message repairs, the speakers start to process a completely different utterance. In this case, the repair does not only take place at the lexical level of language processing, but also has to be processed at the conceptual and semantic level. 
In conclusion, it can be stated that very few self-repairs in the present corpus data coincide with a code-switching environment $(8.5 \% ; n=73 / 856)$. But from these few occurrences almost half involve a direct code-switching situation, that is a code-switch during the repair process. Furthermore, the direction of the code-switching sequence in the analyzed occurrences is relatively balanced (see Table I). It is striking that $56 \%$ of the analyzed self-repairs can be classified either as different message repairs (26\%) or recyclings (30\%), while error repairs constitute only $16 \%$ of the relevant material and replacements only i $5 \%$ (see Table 2 ). These results, as well as their implications for models of bilingual lexical access, will be discussed in the upcoming section.

\section{Discussion}

The previous section provided a qualitative discourse analysis of self-repair mechanisms in bilingual speech of highly fluent French-English bilinguals. The aim of this analysis was to identify self-repair mechanisms in bilingual speech, to classify them according to their type and position and to analyse selected examples.

The FM corpus data only contain a total of $2.4 \%$ of self-repair occurrences $(\mathrm{n}=856 / 35,660)$, out of which only $8.5 \%(\mathrm{n}=73 / 856)$ appear in a code-switching environment. That is, only $0.2 \%(n=73 / 35,660)$ of the overall corpus data consists of self-repairs in bilingual speech. From this very small number, only the half of the code-switches $(49 \% ; n=36 / 73)$ occur during the actual process of self-repair (o.I\% of the overall corpus data; $\mathrm{n}=36 / 35,660$ ). These results agree with the present hypothesis (see Section 3) and the findings in Hlavac (20II) that only very few self-repairs occur in code-switching environments. Still, it remains unclear why highly fluent bilinguals in both sets of corpus data appear to use more self-repairs in monolingual than in bilingual speech.

To apply the results of the present corpus analysis to the level of language selection and the SbP model, it is important to discuss the types of self-repairs and the respective starting point of the code-switching sequence in more detail. As stated in Section 3, different message repairs and appropriateness repairs require a new start of the formulation process, that is they include a return from the lexical level to the higher conceptual and semantic level. Consequently, these types of self-repair cannot give any information about the level of language selection in bilingual speech processing. The self-repair type of recyclings cannot provide any information about language selection processes either, because it includes the repetition of a lexical item in the same language. These three types of self-repairs constitute $64 \%(n=47 / 73)$ of the occurrences in the FM corpus data. Consequently, the hypothesis put forward in Section 3 can be affirmed, in that different message repairs, appropriateness repairs and recyclings occur frequently in code-switching environments. In contrast, only $31 \%$ of the data $(n=23 / 73)$ consists of error repairs and replacements. The relatively small number of replacements $\left(n=I_{I} / 73\right)$ supports the hypothesis from Section 3 that replacements only constitute a very small part of the overall number 
of self-repairs in code-switching environments. This small number is very striking in that it is commonly assumed that bilingual speakers may have recourse to a word from the respective other language in situations of self-repair. Furthermore, it is striking that recyclings occur twice as often as replacements. This result leads to the assumption that highly fluent bilingual speakers prefer recyclings in a repair sequence. This is because recyclings include the repetition of a lexical item in the same language, which does not require a return to a prelexical level.

These results provide additional support for the SbP model by Schwieter and Sunderman (2008) in that they suggest that language selection in language processing of highly fluent bilinguals takes place at a prelexical level.

\section{Conclusion}

The present study has provided new information about the role of self-repair in bilingual language processing.

The relatively small amount of self-repairs occurring in code-switching environments provides interesting insights into the processing of two languages in bilingual lexical access. Despite the high overall frequency of code-switching in the corpus data, only $0.1 \%$ of the analysed self-repairs occur during a codeswitch $(\mathrm{n}=36 / 35,660)$. These findings agree with the findings in Hlavac (20II) in that self-repair occurs infrequently in code-switching environments. This fact appears to be true for alternational and insertional code-switching. Still, a detailed qualitative and quantitative analysis of additional large-scale corpus data of highly fluent bilinguals is needed to obtain unequivocal evidence for this assumption. Furthermore, the present study provided new evidence for language selection in highly fluent bilinguals, which supports the SbP model by Schwieter and Sunderman (2008). The fact that self-repairs infrequently coincide with code-switching leads to the assumption that the selection of languages in highly proficient bilinguals may take place at a prelexical level, as proposed by Schwieter and Sunderman (2008). The small number of replacements in the corpus data, in particular, provide evidence for this hypothesis. A contrastive corpus analysis with speech data of late bilinguals and L2 learners is needed to clarify the role of self-repair mechanisms in bilingual speech as further support for the SbP model. An additional analysis of corpus data of late bilinguals and L2 learners needs to identify if these speakers use more speech errors and self-repairs in code-switching environments. Furthermore, further experimental evidence from early and late bilinguals is needed to supplement the results of the present paper.

\section{References}

Costa, A., Colomé, A. \& Caramazza, A. 2000. Lexical Access in Speech Production: The Bilingual Case. Psicológica 2I (3): 403-437. 
Costa, A., Miozzo, M. \& Caramazza, A. 1999. Lexical Selection in Bilinguals: Do Words in the Bilingual's Two Lexicons Compete for Selection? Journal of Memory and Language 4I (3): 365-397.

Costa, A. \& Santesteban, M. 2004. Lexical Access in Bilingual Speech Production: Evidence from Language Switching in Highly Proficient Bilinguals and L2 Learners. Journal of Memory and Language 50 (4): 49I-5II.

Ehlich, K. \& Rehbein, J. 1976. Halbinterpretative Arbeitstranskriptionen (HIAT). Linguistische Berichte 45: 2I-4I.

FEHringer, C. \& Fry, C. 2007. Hesitation Phenomena in the Language Production of Bilingual Speakers: The Role of Working Memory. Folia Linguistica 4I (I-2): 37-72.

Fox, B., Hayashi, M. \& Jasperson, R. 1996. A Cross-Linguistic Study of Syntax and Repair. In E. Ochs, E.A. Schegloff \& S.A. Thompson (eds.), Interaction and Grammar. Cambridge: Cambridge University Press: $185-237$.

Fox, B. \& JASPERSON, R. 1995. A Syntactic Exploration of Repair in English Conversation. In P.W. Davis (ed.), Alternative Linguistics: Descriptive and Theoretical Modes. Amsterdam: J. Benjamins: 77-I34.

Fox, B., Maschler, Y. \& Uhmann, S. 20io. A Cross-Linguistic Study of Self-Repair: Evidence from English, German, and Hebrew. Journal of Pragmatics 42 (9): 2487-2505.

Fromkin, V. (ed.) 1973. Speech Errors as Linguistic Evidence. The Hague - Paris: Mouton de Gruyter.

Gollan, T., Montoya, R., Cera, C. \& Sandoval, T. 2008. More Use Almost Always Means a Smaller Frequency Effect: Aging, Bilingualism, and the Weaker Links Hypothesis. Journal of Memory and Language 58 (3): 787-8I4.

Gollan, T., Montoya, R. \& Werner, G.A. 2002. Semantic and Letter Fluency in Spanish-English Bilinguals. Neuropsychology I6 (4): 562-576.

Gollan, T., Slattery, T.J., Goldenberg, D., Van Assche, E., Duyck, W. \& Rayner, K. 20II. Frequency Drives Lexical Access in Reading but Not in Speaking: The Frequency-Lag Hypothesis. Journal of Experimental Psychology: General I40 (2): 186-209.

GreEn, D.W. 1986. Control, Activation and Resource: A Framework and a Model for the Control of Speech in Bilinguals. Brain and Language 27 (2): 210-223.

Green, D.W. 1998. Mental Control of the Bilingual Lexico-Semantic System. Bilingualism: Language and Cognition I (2): 67-8I.

Grosjean, F. 20or. The Bilingual's Language Modes. In J.L. Nicol (ed.), One Mind, Two Languages: Bilingual Language Processing. Malden - Oxford: Blackwell: I-22.

GüLICH, E. 1986. L’organisation conversationnelle des énoncés inachevés et de leur achèvement interactif en "situation de contact". DRLAV-Revue de linguistique 34-35: 16I-182.

GÜLICH, E. \& KотsCHI, T. 1987. Reformulierungshandlungen als Mittel der Textkonstitution. Untersuchungen zu französischen Texten aus mündlicher Kommunikation. In W. МотsCH (ed.), Satz, Text, sprachliche Handlung. Berlin: Akademieverlag: 199-26I.

Hlavac, J. 20II. Hesitation and Monitoring Phenomena in Bilingual Speech: A Consequence of Code-Switching or a Strategy to Facilitate Its Incorporation? Journal of Pragmatics 43 (I5): 3793-3806. 
Jefferson, G. 1983. On Exposed and Embedded Corrections. Studium Linguistik 14: 58-68.

Котsсні, T. 1996. Textkonstitutionsstruktur und Informationsstruktur. In W. МотsсH

(ed.), Ebenen der Textstruktur. Spracbliche und kommunikative Prinzipien. Tübingen:

M. Niemeyer: 24I-27I.

Levelt, W.J.M. 1983. Monitoring and Self-Repair in Speech. Cognition I4: 4I-IO4.

Meuter, R.F.I. \& Allport, A. 1999. Bilingual Language Switching in Naming: Asymmetrical Costs of Language Selection. Journal of Memory and Language 4O (I): 25-40.

Mougeon, R., ReHner, K. \& AleXANDRE, N. 2005. Le français parlé en situation minoritaire: choix de langue, identité linguistique et variation linguistique parmi les élèves des écoles de langue française dans cinq communautés franco-ontariennes. Rapport final préparé pour le ministère de l'Éducation de l'Ontario.

RIEGER, C.L. 2000. Self-Repair Strategies of English-German Bilinguals in Informal Conversations: The Role of Language, Gender and Proficiency. $\mathrm{PhD}$ thesis. University of Alberta. Edmonton, Canada.

RIEGER, C.L. 2003. Repetitions as Self-Repair Strategies in English and German Conversations. Journal of Pragmatics 35 (I): 47-69.

Schegloff, E.A., Jefferson, G. \& Sacks, H. 1977. The Preference for Self-Corrections in the Organization of Repair in Conversation. Language 53:36I-382.

Schwieter, J.W. \& Sunderman, G. 2008. Language Switching in Bilingual Speech Production: In Search of the Language-Specific Selection Mechanism. The Mental Lexicon 3 (2): 214-238.

Uhmann, S. 2006. Grammatik und Interaktion: Form Follows Function? - Function Follows Form? In A. Deppermann, R. Fiehler \& T. Spranz-Fogasy (eds.), Grammatik und Interaktion. Untersuchungen zum Zusammenhang von grammatischen Strukturen und Gesprächsprozessen. Radolfzell: Verlag für Gesprächsforschung: 179-202. 